\title{
Per Picoliter
}

National Cancer Institute

\section{Source}

National Cancer Institute. Per Picoliter. NCI Thesaurus. Code C117964.

A volume unit equal to one picoliter used as a denominator to build a derived unit expressed as a ratio. 